\title{
Photo-driven CO2 Reduction to Hydrocarbons: Carbon Flux and Energy Transforming by Marine Microbial Community
}

\section{Wenjie Xia}

Nankai University College of Life Sciences

\section{Rui Chen}

Tianjin Academy of Agricultural Sciences

\section{Yang Li}

Tianjin Institute of Industrial Biotechnology

John Ma

California Institute of Technology

\section{Yongchun Tang}

Power environmental energy research Institute

\section{Ting Ma ( $\nabla$ tingma@nankai.edu.cn )}

Nankai University College of Life Sciences https://orcid.org/0000-0001-9293-4115

\section{Research}

Keywords: Microbial community, Bioconversion, CO2, Hydrocarbons, Photosynthesis, Carbon cycle Posted Date: July 10th, 2020

DOl: https://doi.org/10.21203/rs.3.rs-40882/v1

License: (1) This work is licensed under a Creative Commons Attribution 4.0 International License. Read Full License 


\section{Abstract}

Background: Microbial activities play a crucial role in the carbon and energy cycle of the ocean. Microbial communities in the MCP has been proposed the function of transforming carbon, yet the potential for direct $\mathrm{CO} 2$ reduction to the organic carbon is rarely considered in the carbon cycle and energy transforming.

Results: Here we showed a naturally inherent photo-driven bioprocess of $\mathrm{CO} 2$ reduction producing $\mathrm{C} 1$-C 6 alkanes/alkenes by the marine microbial community with CO 2 consumption rate of $100.87 \mathrm{uM}$ day -1 . Upon the metabolite profiles and metagenomic sequencing analysis, we revealed the mechanism of $\mathrm{CO} 2$ conversion to hydrocarbons that $\mathrm{CO} 2$ fixation was dominantly completed with the Calvin-BensonBassham cycle, tricarboxylic acid cycle, and Wood-Ljungdahl cycle, while nitrogenases, aldehyde decarbonylase and carboxylic acid reductase played the crucial roles on the hydrocarbon formations. As these insights, the pathway of $\mathrm{CO} 2$ to hydrocarbons was proposed. Isolated microorganisms from the enriched community, including Pseudomonas sp. , Serratia sp. , Candidatus sp. , Clostridium sp. , Enterococcus sp ., Salmonella sp. , Rhodospirillum sp. , Thalassospira sp. , Thioclava sp. , Stenotrophomonas sp. and Desulfovibrio sp., were tentatively integrated for validating the hypothesized process. Results exhibited that the improved performance of $\mathrm{CO} 2$ reduction to hydrocarbons was achieved by this group.

Conclusions: This study demonstrated a natural microbial CO 2 reduction process contributing to the carbon and energy cycle in the ocean, and could provide a microbial "CO 2 -hydrogenation process" or "fischer-tropsch process" for industrial application.

\section{Background}

Incessant exploitation and utilization of fossil-derived resources releases significantly large quantities of $\mathrm{CO}_{2}$ over $30 \mathrm{Gt}$ (Gigatonne) annually [1]. The ocean's ability to sequester the atmospheric $\mathrm{CO}_{2}$ exerts an important control on global climate [2-9]. As a significant sink for anthropogenic $\mathrm{CO}_{2}$, it takes up more than $30 \%$ of $\mathrm{CO}_{2}$ emission arising from human activities, as estimated that the volume of $\mathrm{CO}_{2}$ going into the ocean is increasing $[2,3,5,7-9]$. Biological and microbial processes play important role on transforming the anthropogenic $\mathrm{CO}_{2}$ in to ocean [3-5, 9-12]. However, their mechanisms for the carbon sequestration in the ocean need to be further explored $[4,11,12]$. Nearly all biological and biogeochemical processes in the sea are driven with sunlight energy via photosynthesis, there is an inextricable, yet poorly characterized, linkage between carbon fluxes and energy fluxes in the sea $[9,13]$. Biological carbon pump (BCP), largely responsible for the long-term sequestration of $\mathrm{CO}_{2}$ in the euphotic zone into the mesopelagic and abyssal zones, includes all those processes in the ocean that form the 
organic carbon photosynthetically by phytoplankton in the euphotic zone, and thus increase the flux of particulate organic carbon to the deep ocean $[6,9,13,14]$. The phytoplankton systems and its subsequent pathways and mechanisms for carbon cycling and energy dissipation have been paid significant efforts. Yet, the contribution of the microbial activity on carbon and energy cycle, especially in the euphotic zone of the ocean, is less well-understood.

Importance of the microbial communities on regulating the flow of carbon in ocean has been increasingly recognized $[4,9,11-13,15]$. Concepts such as the Microbial Carbon Pump (MCP) have been proposed to preliminarily explain the transformation of bioavailable dissolved organic carbon (DOC) to refractory DOC with MCP and the returning of DOC to the food web as particulate organic carbon $[4,9,12,13,15,16]$. In addition, microbial respiration mobilizes the bioavailable $\mathrm{DOC}$ into $\mathrm{CO}_{2}$, which makes the carbon

available again to be released back to the atmosphere $[4,16,17]$. Within these hypothesized concepts, the carbon pool in the ocean can be fluctuated by the diversity and complexity of marine microorganisms. Particularly, the metabolism networks of the microbial communities are significantly complicated and challenging, and are still being characterized. Majority of the mechanism explanations on the carbon cycle are initiated with the photo-driven fixation of BCP in the sunlit surface waters of the ocean $[4,9,12$, $13,16-18]$. Few of investigation on the microbial fixation of $\mathrm{CO}_{2}$ to the organic carbon in the euphotic zone is taken into account.

Here we showed a photo-driven bioprocess that directly convert $\mathrm{CO}_{2}$ to light hydrocarbons $\left(\mathrm{C}_{1}-\mathrm{C}_{6}\right.$ alkanes and $\mathrm{C}_{2}-\mathrm{C}_{3}$ alkenes) with high selectivity by using the microbial communities enriched from marine water samples. The reduction rate of $\mathrm{CO}_{2}$ was $48.9 \%$ during 50 days culturing. To investigated the metabolic pathway of the microbial community, the analyses of metabolite profiles and metagenomic sequencing indicated that this photo-driven process was initiated with the Calvin-Benson-Bassham cycle, reductive tricarboxylic acid cycle, Wood-Ljungdahl cycle for $\mathrm{CO}_{2}$ fixation, and the hydrocarbon synthesis was completed with nitrogenase and aldehyde decarbonylase. Concomitantly to validate the pathway, we reconstructed an artificial group with specific microorganisms, which showed the improved performances on bioconversion. These specific strains were isolated from the original microbial consortium, and selected according to their abundance in consortium and functions on $\mathrm{CO}_{2}$ fixation and hydrocarbon synthesis. This study shows a natural bioprocess in euphotic zone of ocean for carbon and energy cycle.

\section{Results}

\section{Kinetics of $\mathrm{CO}_{2}$ reduction to Hydrocarbon}

Gas samples were transferred from headspace of bioreactor at intervals to carry out the gas chromatograph analysis. The original profiles of gas chromatogram shown in Figure S3. Results demonstrated that $\mathrm{CO}_{2}$ was obviously utilized at the average consumption rate of $100.87 \mathrm{uM}$ day $^{-1}$ decreasing from $11573.39 \mathrm{uM}$ to $5905.73 \mathrm{uM}$ through 50 days culturing, and converted to light hydrocarbons including $\mathrm{C}_{1}-\mathrm{C}_{6}$ alkanes and $\mathrm{C}_{2}-\mathrm{C}_{3}$ alkenes, when exposed to the consistent LED light. The 
maximum concentration of total light hydrocarbons was $169.67 \mathrm{uM}$ observed at $38^{\text {th }}$ day (Fig. 1a). The reduction rate of $\mathrm{CO}_{2}$ was $48.9 \%$ during 50 days culturing. The selectivity of $\mathrm{C}_{2}-\mathrm{C}_{5}$ was more than $80 \%$.

${ }^{13} \mathrm{C}$-labeled $\mathrm{CO}_{2}$ was applied to track the carbon flux and confirm the carbon origin. In the light of GC-MS data shown in Fig. S4, the feeding of ${ }^{13} \mathrm{CO}_{2}$ resulted in the incorporation of isotopic labelling into light hydrocarbons as indicated by the molecular ion, which was increased by 1 to 6 for each alkane or alkane. The fragment ions were also increased by 1 to 5 . Methane production as shown in Fig. 1b, was primarily detected at early stage of our bioprocess, and reached the maximum value of $66.22 \mathrm{uM}$ at $31^{\text {st }}$ day. During the period from $4^{\text {th }}$ to $17^{\text {th }}$ day, the production rate of methane was highest at $3.99 \mathrm{uM} \mathrm{day}^{-1}$. Except methane, other light hydrocarbons were negligibly detected in the headspace before $31^{\text {st }}$ day, but significantly observed after longer time cultivation coupling with the decreasing of methane concentration. After that, n-Butane was dominant in the mixture of light hydrocarbons, the maximum value of 44.09 uM was measured by gas chromatograph at $38^{\text {th }}$ day, which was approximately 42.68 -fold of ethane, 2.47-fold of propane, 4.58-fold of i-butane, 3.88-fold of i-pentane, 1.76-fold of n-pentane, 17.72fold of i-hexane, and 53.64-fold of n-hexane (Fig. 1b). In addition, the isomer type of alkane was less than the normal alkane within our bioprocess, even compared with same carbon number. This trend showed the conformity with the theory of classic geochemistry that the ratio of the isomer type against the normal type generated in biological process was generally less than 1 in contrast with the geothermal process $[19,20]$. Such kinetics of hydrocarbons generation from $\mathrm{CO}_{2}$ demonstrated the marine microorganisms hold the significant ability to transform the $\mathrm{CO}_{2}$ and solar energy to the organic chemicals.

\section{Microbial diversity and statistical analysis of protein category representation}

16S rRNA genes and metagenomic sequencing were performed to investigate the microbial structure the function within the $\mathrm{CO}_{2}$ reduction process. By $16 \mathrm{~S}$ rRNA gene sequencing, a total of 765,416 sequencing reads were generated and the reads were grouped into 4,240 operational taxonomic units (OTUs). 12 OTUs accounted for $98 \%$ to $99 \%$ of the total community, and prevalently distributed in all samples $(>0.5 \%$ of the retrieved sequences, Fig.2): Proteobacteria, Firmicutes, Basidiomycota, Actinobacteria, Ascomycota, Fusobacteria, Chytridiomycota, Tenericutes, Synergistetes, Mucoromycota, Cyanobacteria and Euryarchaeota. Among them, Proteobacteria (>75\% of the retrieved sequences) was accounted for dominate abundance in all samples. The subdivision, including alphaproteobacteria, betaproteobacteria, gamaproteobacteria, deltaproteobacteria and epsilonproteobacteria were detected in all samples.

Particularly, gamaproteobacteria with obviously higher percentage (39.88\% in S1, 85.91\% in S2, 93.56\% in S3, and $96.35 \%$ in S4) was increased along with culturing, which have been extensively reported that most of this subdivision are capable of photoautotrophic pathway or chemolithoheterotrophic pathway for $\mathrm{CO}_{2}$ fixation [21-24]. Cyanobacteria, Ignavibacteriae, Chlorobi, and Bacteroidetes were only detected in sample $\mathrm{S} 1$, which have been well-elaborated the capacity of $\mathrm{CO}_{2}$ fixation, nitrogen fixation, and hydrogen production via photoautotrophy or chemolithoautotrophy, yet the phylum (like Ignavibacteriae, Chlorobi, etc) were sensitive to oxygen [22-26]. Oxygen, possibly generated from the oxygenic photoautotroph like 
Cyanobacteria, was detected (data shown in Fig. 1a). Consequently, the abundance of these oxygensensitive and $\mathrm{CO}_{2}$-fixing phylotypes was lower than other, even cannot be detected along with culturing (Fig. 2).

We annotated the gene catalogues by NR, KEGG and eggNOG according to metagenomic sequencing. The statistics of the annotation was listed in Table S2. Protein sequences within specific categories were analyzed to statistically identify protein categories found in each sample. According to functional categories, the predicted genes assigned to energy production and conversion had the highest proportion (Fig. 3). At the functional level, it was obviously observed that functional structures of four samples were changed during culturing, as unique KEGG orthologue group (KO) profile in sample S3 and S4 showed lower diversity than the sample S1 and S2 (Figure S5a). At pathway level, the subculture enriched Kos were distributed in carbon fixation and hydrocarbon synthesis. Genes encoding the carbon fixation enzyme in sample S1 and S2 was approximately 2 folds in sample S3 and S4 (Figure S5b).

\section{Metabolic pathways and key microorganisms involved in carbon dioxide fixation}

According to the data of metagenomic sequencing and KEGG database, six natural $\mathrm{CO}_{2}$-fixation pathways and the relevant key genes, including the Calvin-Benson-Bassham (CBB) cycle, the 3hydroxypropionate cycle, the Wood-Ljungdahl (WL) pathway, the reductive tricarboxylic acid (rTCA) cycle, the dicarboxylate/4-hydroxybutyrate cycle, and the 3-hydroxypropionate-4-hydroxybutyrate cycle, have been analyzed to predict the potential pathway for such bioconversion process. As well known, the CBB cycle, the 3-hydroxypropionate cycle, and 3-hydroxypropionate-4-hydroxybutyrate cycle were operated under aerobic condition, while the others pathways were anaerobic. Given all six pathways involved in our bioconversion process, the transition of pathways must be occurred during culturing, referring to the oxygen kinetics shown in Fig. 1a. Alignment to KEGG database, it presented that CBB cycle, rTCA cycle and WL pathway were completed, while the others were incomplete in all samples (Fig. S6). Key genes of these completed pathways, namely RubisCO for CBB cycle [23, 27-29], ATP citrate lyase for rTCA cycle $[22,23,25]$ and $C O$ dehydrogenase/acetyl-CoA synthase for WL pathway $[23,30]$ were detected and showed the significant abundance in all samples (Fig. 4a), demonstrating that the microbial communities embodied the ability of autotrophic carbon fixation. Represented by the key genes, the abundance of CBB cycle was decreased during culturing, while the abundance of rTCA cycle and WL pathway were increased (Fig. 4b). This phenomenon indicated that $\mathrm{CO}_{2}$ reduction was possibly initiated with $\mathrm{CBB}$ cycle, and switched to rTCA cycle and WL pathway, when oxygen was depleted or lower than the critical sensitive concentration (Fig. 1a). According to the accumulated gene abundance of such three pathways from metagenomic analysis, the structural dynamics of the microbial consortium in phylum level suggested that Proteobacteria (51.5\%-75.6\%), Firmucutes (9.6\%-19.7\%), Acinobacteria (6.8\%-14.8\%) and Euryarchaeota $(2.2 \%-7.8 \%$ ) accounting for relative larger abundance were the main taxa responsible for $\mathrm{CO}_{2}$ fixation (Figure S7a-S7c). Numerous literatures have demonstrated that CBB cycle was operated in Alpha-and Gammaproteobacteria, rTCA cycle had been found in representatives of the Epsilonproteobacteria, and WL pathway was continually reported on Proteobacteria, Firmucutes, Acinobacteria and Euryarchaeota [22-26, 31, 32]. 
The contigs representing $76.8 \%$ of the total sequence data in all samples were binned into the highquality genome bins. 23 of the genome bins recovered were identified as prevalent OTUs. Phylogenetic tree was constructed and presented the placement of the selected bins in the relevant phylum or subdivision (Figure S8). Among of them, Nostoc (bin 1), Anabaena (bin 2) and Synechocystis (bin 3) within the phylum of Cyanobacteria, belonging to the oxygenic phototrophs encoding RuBisCO, were detected and showed the abundance of less than $2 \%$ in all samples, while their abundance were relatively higher in sample S1 than that in other samples. Nostoc and Anabaena were only detected in sample S1, and Synechocystis was not detected in samples S3 and S4. Although the oxygenic phototrophs showed their presence, anoxygenic $\mathrm{CO}_{2}$-fixation phylotypes were dominated in all samples, which included Brucella (bin 4), Serratia (bin 5), Shigella (bin 6), Candidatus (bin 7), Chlorobium (bin 8), Azospirillum (bin 9), Azotobacter (bin 10), Vibrio (bin 11), and Simiduia (bin 12) (Figure S7c-S7e). Species from Brucella and Vibrio genus were facultative $\mathrm{CO}_{2}$-dependence bacteria capable of producing amino acid, alcohol, aldehyde, etc. [33,34], which can produce the intermediates for hydrocarbon synthesis. Facultative Candidatus genus, capable of $\mathrm{CO}_{2}$ fixation via $\mathrm{CBB}$ cycle or rTCA cycle respectively with or without oxygen, has recently been described an intra-aerobic function that is assumed to generate internal oxygen to facilitate bioreaction of those aerobic pathways [35]. This insight provided the possibility of oxygenic bioreactions of hydrocarbon synthesis by aldehyde decarbonylase (AD) under anaerobic condition. Speices from Serratia genus were well characterized by chemolithotrophic fixation of $\mathrm{CO}_{2}$ which was supported by the presence of RuBisCo, carbonic anhydrase, and carboxylases [36].

As shown in Fig. 4, key gene abundance of WL pathway and rTCA cycle were increased during cultivation, and higher than that in CBB cycle. Chlorobium sp. (bin 8), as anaerobic phototrophs fixing $\mathrm{CO}_{2}$ via a rTCA cycle [25], was detected with increasing abundance in the enrichment starting from $17^{\text {th }}$ day, however showed the negligible percentage at the beginning of culturing. The archaeon Halobacterium (bin 13) was detected which can capture light energy to assimilate $\mathrm{CO}_{2}$ [37]. Based on KEGG database, the specific members of Halobacterium entailed enzymes that can proceed the WL pathway to fix $\mathrm{CO}_{2}$.

WL pathway was regarded as the only pathway known that fixes $\mathrm{CO}_{2}$ while conserving energy as ATP in numerous, phylogenetically disparate, anaerobic prokaryotes widespread within Bacteria and Archaea $[18,20,38,39]$. Mostly within the phylum of Firmicutes (shown in Fig. 2), Acetobacterium woodii, Moorella thermoacetica, Hydrogenotrophic methanogens, Clostridium aceticum, and autotrophic sulfatereducing prokaryotes inherently carried out WL pathway [18-20]. As intermediate of WL pathway, CO was detected during culturing, which is reduced from $\mathrm{CO}_{2}$ by carbon monoxide dehydrogenase (CODH) [36, 37]. Metagenomic analysis of genes encoding the enzymes CODH showed that the abundance of the taxa, including Clostridium (bin 8), Carboxydothermus (bin 14), Rhodospirillum (bin 15), Pseudomonas (bin 16) and Methanosarcina (bin 17), were more than $5 \%$, and increased during culturing. These microorganisms can be capable of fixing $\mathrm{CO}_{2}$ via WL pathway [38-40]. Pseudomonas sp.(bin 16), belonging to the subdivision Gammaproteobacteria, was reported its ability of fix $\mathrm{CO}_{2}$ via WL pathway [41], and showed the abundance was accounted for more than $5 \%$ in all samples, and particularly more 
than $15 \%$ in sample S3 and S4. WL pathway involved within Methanosarcina (bin 17) in the phylum of Euryarchaeota have also been well documented [42].

\section{Pathways and key microorganisms involved in hydrocarbon synthesis}

Recent researches and developments in biofuels have revealed an assortment of enzymes that can catalyze fatty acids, alcohol, or aldehyde to hydrocarbons [21, 25, 27, 29, 43-45], and particularly elaborated the significant role of carboxylic acid reductase (CARs), aldehyde decarbonylase, and nitrogenase in the production of alkane or alkene [20, 29, 30,46]. Generally, the activity of AD from microbes is oxygen-dependently triggered. CARs can catalyze the reduction of a carboxylic acid substrate to the corresponding aldehyde, which can be substrate to AD. As presented in Fig. 1a, the concentration of oxygen reached the maximum value $(20.64 \mathrm{uM})$ at $4^{\text {th }}$ day, then declined to $0.28 \mathrm{uM}$ within 13 days culturing. It was therefore possible that hydrocarbon synthesis could be completed with AD. Metagenomic analysis showed that the abundance of genes for AD were lower in all samples (Fig. 5a). The species from the phylum of Cyanobacteria, which can express $A D$, had relatively lower abundance when compared with others (Fig. 2). Vibrio genus, belonging to Gammaproteobacteria, was similarly reported about the synthesis of alkanes via the AD catalysis, however only even-carbon-number and longchain $\left(>\mathrm{C}_{10}\right)$ alkanes were produced [48]. Therefore, the synthesis of light hydrocarbons via the catalysis of $C A R$ and $A D$ was minimal.

Nitrogenases, including three homologous nitrogenase enzymes that documented as the Mo nitrogenase, $\checkmark$ nitrogenase and Fe-only nitrogenase, were extensively reported to convert small molecules (such as cyanide ions, carbon monoxide, acetate, butanol, butyrate, cyclohexane carboxylate, ethanol, fumarate, succinate, formaldehyde or acetaldehydes) with reductant to alkanes and alkenes under ambient conditions [18, 27, 43-45]. In our study, nitrogen was consumed with rapid decreasing rate at $200.88 \mathrm{uM}$ day $^{-1}$ from $15859.38 \mathrm{uM}$ to 12444.43 uM before $17^{\text {th }}$ day (Fig. 1a), indicating the energetic activity of nitrogenase. Metagenesis analysis showed that the abundance of key genes for nitrogenase were significantly higher in all samples, and increased through cultivation (Fig. 5a). Particularly, Mo nitrogenase and Fe-only nitrogenase accounted for more than $50 \%$ of all types in all samples (Fig. 5 b), which were currently well-reported the performance on catalyzing the reduction of $\mathrm{C}_{1}$ substrates including $\mathrm{CO}$ and $\mathrm{CO}_{2}$ to hydrocarbons [43-45]. According to metagenomic analysis, Shigella (bin 6), Candidatus (bin 7), Clostridium (bin 8), Azospirillum (bin 9), Azotobacter (bin 10), Vibrio (bin 11), Rhodospirillum (bin 15), Pseudomonas (bin 16), Desulfovibrio (bin 18), and Deinococcus (bin 19), were dominantly observed in all samples (Fig. S9), which were capable of secreting nitrogenase especially Mo and Fe-only types under aerobic or anaerobic conditions [18, 22, 43-45]. Furthermore, the abundance of the facultative and obligate anaerobic microbes, like Clostridium, Pseudomonas and Desulfovibrio, were increasingly detected along with depletion of oxygen (Fig. S9). Pseudomonas (bin 16), Rhodospirillum (bin 15), Rhodopseudomonas (bin 20), Rhodobacter (bin 21), Dickeya (bin 22) and Enterococcus (bin 23), belong to the phylum of Proteobacteria, had the intrinsic property of expressing the Fe-only nitrogenases to produce an amount of $\mathrm{CH}_{4}$ and $\mathrm{NH}_{3}$ with light and $\mathrm{CO}_{2}$ and $\mathrm{N}_{2}[18,43-45]$ This evidence confirmed the 
conspicuous phenomenon of $\mathrm{CH}_{4}$ production and $\mathrm{N}_{2}$ fixation at the beginning of culturing when oxygen was in the presence. Other phototrophic bacteria, Rhodospirillum and Rhodobacter, and Azotobacter were detected, and each can produce $\mathrm{CH}_{4}$ when grown with $\mathrm{N}_{2}$ as a sole nitrogen source under Fe-only nitrogenase expressing condition $[18,43-45,48]$.

As one of potential reductant, $41.44 \mathrm{uM}$ of hydrogen was detected at $4^{\text {th }}$ day, then dropping extensively to $9.51 \mathrm{uM}$ at $17^{\text {th }}$ day, and eventually to $0.57 \mathrm{uM}$ at $53^{\text {rd }}$ day (Fig. 1a). Metagenomic analysis for hydrogenase and hydrogenlyase genes showed Clostridium (bin 8) and Vibrio (bin 11) accounted for high abundance in samples (Figure S10). Such two genus are capable of hydrogen generation [18, 39, 42].

Based on the analysis of metabolite profiles and metagenomic sequencing, the pathway from $\mathrm{CO}_{2}$ to light hydrocarbons was proposed as shown in Fig. 6 that $\mathrm{CO}_{2}$ fixation was mainly started with $\mathrm{CBB}$ cycle, then transferred to rTCA cycle and WL pathway along with oxygen depletion, providing various precursors and energy for the process of hydrocarbons synthesis. Subsequently, the synthesis of $C_{1}-C_{6}$ hydrocarbons were mainly catalyzed by nitrogenases. Particularly, the synthesis of methane, observed at the beginning of culturing, was aerobically proceeded by nitrogenase.

\section{Biogroup reconstruction for $\mathrm{CO}_{2}$ conversion to hydrocarbons}

In order to validate the proposed pathway, the isolation of the specific microbes from the enriched communities was conducted under various conditions. 56 strains were obtained, and identified by $16 \mathrm{~S}$ rRNA sequencing. Among of them, some facultatively and obligately anaerobic strains (deposited as GeneBank access No. MN538968 to MN538983) shown in Table S3 were purposely selected for the reconstruction of a biogroup to tentatively perform the bioconversion of $\mathrm{CO}_{2}$ to light hydrocarbons under the original condition, according to the analysis of the $16 \mathrm{~S}$ rRNA and metagenomic sequencing, as well as the previous reports of their performances. The selected strains, including Pseudomonas sp., Serratia sp., Candidatus sp., Clostridium sp., Sporomusa sp., Salmonella sp., Rhodospirillum sp., Thalassospira $s p$. ., Thioclava sp., Stenotrophomonas $s p$. and Desulfovibrio $s p$., had relative higher abundance in microbial communities, and have the functions on the proceeding of CBB, rTCA, WL pathway and encoding $A D$ and nitrogenases. Gas chromatography showed that the reconstructed biogroup had ability of $\mathrm{CO}_{2}$ reduction to the light hydrocarbons (Fig. 7). The maximum concentration of total light hydrocarbons was $42.97 \mathrm{uM}$ observed at $7^{\text {th }}$ day (Fig. 7a). $\mathrm{CO}_{2}$ was obviously assimilated at the average catabolic rate of $107.54 \mathrm{uM} \mathrm{day}^{-1}$ by decreasing from $5617.89 \mathrm{uM}$ to $241.01 \mathrm{uM}$ through 50 days culturing, which was higher than the rate of the original communities shown in Fig 1a. Nitrogen was reduced with rapid decreasing rate at 299.01 uM day $^{-1}$ in first three days (Fig. 7a), which was higher than $161.93 \mathrm{uM} \mathrm{day}^{-1}$ of the original communities, indicating more intensive activities of nitrogenase by the reconstructed biogroup. $12.69 \mathrm{uM}$ of hydrogen was detected at $3^{\text {rd }}$ day, then dropped extensively to 0.51 $\mathrm{uM}$ at $7^{\text {th }}$ day and eventually to $0.07 \mathrm{uM}$ at $50^{\text {rd }}$ day. Compared with process by the original communities, obvious difference was observed that all light hydrocarbons were simultaneously produced by this biogroup, and most of them presented the highest production rate in early three days, while were 
decreased after $30^{\text {th }}$ day. n-Butane and n-pentane were dominant hydrocarbon in the mixture, the maximum value of $10.62 \mathrm{uM}$ at $18^{\text {th }}$ day and $12.75 \mathrm{uM}$ at 7 days were respectively measured (Fig. $7 \mathrm{~b}$ ). The original profiles of gas chromatography from the reconstructed biogroup was presented in Figure S11. These difference between the original communities and the reconstructed biogroup indicated some specific microorganisms play important role on the efficiency and direction of hydrocarbon synthesis. Therefore, the exploration and identification of the specific microbes, and microbial diversity need more further works.

\section{Discussion}

Microbial community plays an important role on the carbon and energy cycle in ocean, and shows the significant diverse functions on the carbon flux [3-10, 12-17]. As presented in Fig. 1, we found the marine microbial communities exhibited the significantly impressive performance on $\mathrm{CO}_{2}$ reduction and hydrocarbon synthesis, the total yield, the metabolite diversity, the production rate, and the consumption rate of $\mathrm{CO}_{2}$ were obviously higher than the literatures described with soil microbial communities, pure microorganisms or enzymes [18, 35-39, 43-50]. In ocean, the role of phytoplankton on the carbon flux ( $\mathrm{CO}_{2}$ reduction) was well acknowledged. Bacteria in the ocean that mediate the $\mathrm{MCP}$, are reported to substantially influence the carbon cycle of the earth system. As tremendously described [2-10], they take up labile organic carbon produced by phytoplankton, and transfer it into the recalcitrant form that can resist from degradation for thousands of years. However, rare of efforts on microbial reduction of $\mathrm{CO}_{2}$ to organics and its mechanism was paid to demonstrate the carbon and energy flux in ocean. The quantitative comparison of $\mathrm{CO}_{2}$ fixation between the microbial community and the phytoplankton, which can putatively measure the percentage of carbon sequestration for each, was not carried out for herein. But, the metabolic kinetics of $\mathrm{CO}_{2}$ conversion to hydrocarbons shown in Fig. 1 indicated the astonishing efficiency and comparable contribution on sequestrating $\mathrm{CO}_{2}$ by microbial communities in the euphotic zone of the ocean.

Numerous literatures reported the hydrocarbons production via genetic manipulation on specific bacteria, but generally $\mathrm{CO}_{2}$ was not involved [10,30,31,49] or other metabolites (like aromatic hydrocarbons, alcohols, acids, aldehydes, etc.) were targeted initiating with $\mathrm{CO}_{2}$ reduction $[9,32,33]$. Metabolism networks of the microbial communities are significantly complicated and challenging, and are still being characterized due to it's the flexibility and diversity of functions on bioconversion [11-16]. Associated with the profile of the metabolites, the mechanism of $\mathrm{CO}_{2}$ conversion by marine microorganisms was explored according to the metagenomic sequencing that the important role of CBB cycle, rTCA cycle and WL cycle on $\mathrm{CO}_{2}$ reduction, and nitrogenases and $\mathrm{AD}$ on hydrocarbon synthesis were tentatively validated. Although each of these pathways have been elaborated well respectively, the synergy of them focusing on $\mathrm{CO}_{2}$ reduction to hydrocarbon as we found is rarely reported [11-16, 18, 35-39, 43-50]. Key genes of three $\mathrm{CO}_{2}$ fixing pathways for encoding specific enzymes, namely RubisCO for CBB cycle, ATP citrate lyase for rTCA cycle and CODH/acetyl-CoA synthase for WL pathway, were detected and showed 
the significant abundance in samples (Fig. 4a). Other enzymes like AD and nitrogenase showed their attractive functions on hydrocarbon synthesis with aliphatic acids or carbon monoxide as substrate, however the total yield, production rate of hydrocarbons, and consumption rate of $\mathrm{CO}_{2}$ were lower when comparison with the process we discovered $[18,20,22-24,27,51,52,60]$. The function of aldehyde dehydrogenase to convert aliphatic acids to alkane is generally fulfilled with the involvement of oxygen $[21,25,27,39,46,52]$. Therefore, hydrocarbon synthesis via aldehyde dehydrogenase was limited due to the minimal concentration of oxygen (Fig. 1) within our process. Nitrogenase, known for its key role in the global nitrogen cycle, catalyzing the ambient reduction of atmospheric $\mathrm{N}_{2}$ to bioavailable $\mathrm{NH}_{4}{ }^{+}[48]$, has been increasingly reporting in recent literatures due to its novel function to reduce $C_{1}$ substrates, such as $\mathrm{CO}$ and $\mathrm{CN}^{-}$to short hydrocarbons with the presence of the reductants [43-45,48], while the characteristics of these reported processes was obviously characterized that methane was dominant in final products. All of these indicated the complexity of this metabolic network and diverse functions within our enriched microbial community. Fortunately, we preliminarily hypothesized the pathway of $\mathrm{CO}_{2}$ conversion to hydrocarbons of marine microorganisms, based on the obtained metabolic kinetics and metagenomic analysis.

Subsequently, an artificial biogroup was reconstructed with the specific microorganisms isolated from the enriched communities showed the higher rate of $\mathrm{CO}_{2}$ and $\mathrm{N}_{2}$ fixation, and similar activities of light hydrocarbon synthesis, aiming to verify the possible mechanism. These strains inherently hold the functions on $\mathrm{CO}_{2}$ reduction or hydrocarbon synthesis [21-46]. Interesting, their synergy made the high flexibility of $\mathrm{CO}_{2}$ conversion. Through this study, an inherent and effective bioprocess in euphotic zone of the ocean was recognized, which exhibited the carbon and energy flux from $\mathrm{CO}_{2}$ to hydrocarbons by microbial activities.

\section{Conclusion}

A photo-driven bioprocess that directly fix $\mathrm{CO}_{2}$ to light hydrocarbons $\left(\mathrm{C}_{1}-\mathrm{C}_{6}\right.$ alkanes and $\mathrm{C}_{2}-\mathrm{C}_{3}$ alkenes $)$ with high selectivity by marine microbial communities was discovered. The reduction rate of $\mathrm{CO}_{2}$ was $48.9 \%$ during 50 days culturing. Mechanisms of such bioprocess was preliminarily described according to metabolic kinetics and metagenomic sequencing, and indicated that the CBB cycle, rTCA cycle and WL pathway were responsible for $\mathrm{CO}_{2}$ fixation, and nitrogenase played dominant role on hydrocarbon synthesis. Tentative efforts to artificially develop a biogroup with using the isolated strains from the enrichment including Pseudomonas sp., Serratia sp., Candidatus sp., Clostridium sp., Enterococcus sp., Salmonella sp., Rhodospirillum sp., Thalassospira sp., Thioclava sp., Stenotrophomonas sp. and Desulfovibrio sp., were successfully made to simulate such bioconversion process. This study presented a natural bioprocess in euphotic zone of ocean for carbon and energy cycle. Additionally, this bioprocess could be further optimized and provide a microbial " $\mathrm{CO}_{2}$-hydrogenation process" or "fischer-tropsch process" for industrial application. 


\section{Methods}

\section{Samples, cultures, $\mathrm{CO}_{2}$ conversion}

500 milliliters of water samples fetched from beach (location shown Figure S1) were filtrated for cell collection, then suspended in sterilized water and transferred into 1000 milliliters of pyrex reaction vessel (Figure S2) which supplemented with mineral salts medium (including g $\mathrm{L}^{-1}: 0.3 \mathrm{~K}_{2} \mathrm{HPO}_{4}, 0.3 \mathrm{NaH}_{2} \mathrm{PO}_{4}$, $0.05 \mathrm{MgSO}_{4}, 0.01 \mathrm{FeSO}_{4}, 1.0 \mathrm{CaCO}_{3}, 0.1 \mathrm{NaNO}_{3}$ ), and finally sealed and exposed to white LED light (6 mol photons $\mathrm{m}^{-2} \mathrm{~s}^{-1}$ ) for culturing. The vessel was purged with nitrogen gas, and 30 milliliters of $\mathrm{CO}_{2}$ (Research 5.0 Grade, Airgas, USA) with $29.29 \mathrm{psi}\left(25^{\circ} \mathrm{C}\right)$ was syringed into the glass reactor as carbon source. At intervals, 30 milliliters of the collected samples from the reactor was syringed into to a new autoclaved tube for further analysis. Samples collected at $4^{\text {th }}, 17^{\text {th }}, 31^{\text {st }}, 38^{\text {th }}$ day during the culturing were labeled as S1, S2, S3, S4 respectively.

\section{Gas chromatograph determination of hydrocarbons}

Alkane and alkene analysis were carried out with a gas chromatographs (Capillary FID GC System, SRI Instruments, USA) equipped an 8600-WB5B 30M×0.53mm I.D.1.0u DB-5 Type MXT-5 capillary column [19, 20]. One microliter of the headspace gas was syringed into $10: 1 \mathrm{split}$ mode (1.9 $\mathrm{ml} \mathrm{min}^{-1} \mathrm{He}$ flow), the testing program: initial temperature $35^{\circ} \mathrm{C}$, hold $7 \mathrm{~min}$; ramp $15^{\circ} \mathrm{C} \mathrm{min}^{-1}$ to $180^{\circ} \mathrm{C}$, hold $7 \mathrm{~min}$ at $180^{\circ} \mathrm{C}$; ramp $20^{\circ} \mathrm{C} \mathrm{min}^{-1}$ to $245^{\circ} \mathrm{C}$; hold $9 \mathrm{~min}$ at $245^{\circ} \mathrm{C}$. Short-chain hydrocarbon was confirmed by comparison with a commercial standard (Airgas, USA). Quantification was completed by relating the GC peak area of the sample to the peak area of the standard alkane and alkene gas mixtures (Praxair, Geismar, LA), which were obtained from the headspace of sealed culture vials. In all cases, three replicates were carried out in parallel.

\section{Gas chromatography-mass spectrometry validation}

For the validation of the carbon flux, the produced hydrocarbons with using ${ }^{13} \mathrm{C}$ labeled $\mathrm{CO}_{2}$ were identified by GC-MS using a Thermo Trace 1300 GC coupled to an ISQ-QD GC-MS (Thermo Fisher Scientific Inc., USA) $[19,20]$. A total of $1 \mathrm{ml}$ headspace gas was injected, and operated at $125^{\circ} \mathrm{C}$ in splitless mode. Gas separation was achieved on a Restek (Bellafonte, PA) PLOT-QS capillary column $\left(0.320 \mathrm{~mm} \mathrm{ID} \times 30 \mathrm{~m}\right.$ length), which was held at $40^{\circ} \mathrm{C}$ for $2 \mathrm{~min}$, heated to $180^{\circ} \mathrm{C}$ at $10^{\circ} \mathrm{C} / \mathrm{min}$, held at $180^{\circ} \mathrm{C}$ for $1 \mathrm{~min}$, heated to $220^{\circ} \mathrm{C}$ at $40^{\circ} \mathrm{C} / \mathrm{min}$, and finally held at $220^{\circ} \mathrm{C}$ for $2 \mathrm{~min}$. The carrier gas, helium $(\mathrm{He})$, was passed through the column at $1.1 \mathrm{~mL} / \mathrm{min}$. The mass spectrometer was operated in electron impact (EI) ionization and selected ion monitoring (SIM) mode.

\section{Total DNA extraction}

Total metagenomic DNA was isolated from $30 \mathrm{~mL}$ of each sample using the QIAamp DNA Mini Kit (Qiagen, California, USA) according to the manufacturer's protocol. Quality and molecular weight of the 
DNA extracts were evaluated by agarose gelelectrophoresis. Quantity and 260/280 nm absorbance ratio as a measure of DNA purity was determined with NanoDrop ${ }^{\circledR}$ ND-1000 Spectrophotometer (Thermo Fisher Scientific, Wilmington, DE, USA) and Qubit fluorometer (Life Technologies, Carlsbad, CA, USA). All DNA extracts were stored at $-20^{\circ} \mathrm{C}$ until further processing.

\section{Taxonomic assignments based on 16S rRNA sequencing}

The variable V3-V4 region of $16 \mathrm{~S}$ rDNA was amplified using primer sets Bac336F/Bac806R for bacteria and Arc334F/Arc806R for archaea $[53,54]$. Indexing sequences (10 nt) were added to the $5^{\prime}$ end of the forward and reverse primers for differentiating multiple samples. Amplification primers were derived from standard Illumina adapters, and PCR reaction was carried out according to the method described previously [55]. The concentration of the amplified libraries was determined by quantification with RealTime PCR to confirm the presence of suitable primers for Illumina sequencing. Paired-end sequencing with read length of $300 \mathrm{bp}$ was performed on Miseq platform. Raw reads that had a low-quality score ( $\leq 20$ for more than $10 \%$ ) or did not match to primer and index sequences were discarded for subsequent analysis. The Quantative Insights Into Microbial Ecology (QIIME, version 1.8.0) software was used to process these high-quality reads and calculate the abundance and composition of microbial communities [56]. A similarity threshold of $97 \%$ was set for clustered operational taxonomical units (OTUs) according to the Greengenes reference database [57].

\section{Metagenomic sequencing}

For each water sample a shotgun library was constructed. The libraries were prepared using the NEBNext ${ }^{\circledR}$ Ultra ${ }^{\mathrm{T}}$ DNA Library Prep Kit for Illumina ${ }^{\circledR}$ (New England Biolabs, UK). The libraries were size selected using Agencourt ${ }^{\circledR}$ AMPure ${ }^{\circledR}$ XP beads (Beckman Coulter, Pasadena, CA, USA) with a bead to DNA ratio of 0.6 to $1\left(\mathrm{v} \mathrm{v}^{-1}\right)$. Quality and purity of the libraries has been analyzed with the High Sensitivity DNA Analysis Kit (Agilent Technologies, Santa Clara, CA, USA) on a 2100 Bioanalyzer (Agilent Technologies, Santa Clara, CA, USA). The libraries were quantified using the KAPA Library Quantification Kits (Kapa Biosystems, Wilmington, MA, USA). Sequencing was performed on Illumina Hiseq ${ }^{\circledR} 2500$ sequencing system (IIlumina, San Diego, CA, USA) with the HiSeq PE Cluster Kit v4 cBot and HiSeq SBS Kit v4 (Illumina, San Diego, CA, USA) in a paired end mode ( $2 \times 150 \mathrm{bp})$.

\section{Bioinformatic analysis}

Raw reads were quality-filtered and the sequencing adaptors were removed by using Trimmomatic software (V0.35) with default parameters [58]. MEGAHIT was used for de novo assembly of clean reads with the "meta-large" preset [59]. For each assembled contig, automated gene annotation was performed by using Prokka program. Salmon was utilized to calculate the normalized abundance for each annotated gene. Maxbin and MetaBAT2 were used for metagenomic binning analysis to recover individual genomes $[60,61]$. 
The species profiling analysis was accomplished by self-built databases and customized Perl scripts. In brief, the taxonomy databases were downloaded from NCBI

(ftp://ftp.ncbi.nlm.nih.gov/pub/taxonomy/accession2taxid/) and EBI

(ftp://ftp.ebi.ac.uk/pub/databases/taxonomy/) for linking the accession ID, taxonomic number and lineage information. And then, the NT database was downloaded and all microbic sequences were extracted, including archaea, bacteria, fungi, viroids and viruses. Subsequently, annotated genes were BLASTN against this micro-NT database, and only the best hit was extracted for species abundance analysis. At last, the species distribution on each taxonomic level could be calculated by using the sum of normalized abundance of best-hit genes for each sample.

For functional analysis, available information of genes, modules and pathways was collected from the kyoto encyclopedia of genes and genomes (KEGG) database as the reference system [62]. For each dataset, previous annotated genes were compared with known KEGG genes by using BLASTP (E-value < 1e-5). Only the best-hit pair was extracted for abundance estimation of designated gene families. For specified pathways or modules, the sum of abundance of the complete set of genes was deemed as normalized values for comparative analysis between samples. All raw reads of $16 \mathrm{~S}$ rRNA and metagenomic sequencing had been deposited at Sequence Read Archive under accession number PRJNA577349 and PRJNA512068.

Metagenomic sequencing of all samples generated total $80.66 \mathrm{~Gb}$ raw reads. Subsequent data cleaning and Megahit assembly resulted in $327.3 \mathrm{Mbp}$ of sequences in 334039 contigs, with an average size of $980 \mathrm{bp}$ and an N50 of $1669 \mathrm{bp}$. Approximately $98.85 \%$ of clean reads could be mapped back to the assembled contigs. The statistics of sequencing data of each sample was tabulated in Table S1.

\section{References}

1. Luderer G, Vrontisi Z, Bertram C, Edelenbosch OY, Pietzcker RC, Rogelj J, et al. Residual fossil $\mathrm{CO}_{2}$ emissions in $1.5-2{ }^{\circ} \mathrm{C}$ pathways. Nature Clim Change. 2018;8:626.

2. Dietmar Müller R, Dutkiewicz A. Oceanic crustal carbon cycle drives 26-million-year atmospheric carbon dioxide periodicities. Sci. Adv. 2018;4(2):eaaq0500.

3. Pabortsava K, Lampitt RS, Benson J, Crowe C, McLachlan R, Le Moigne FAC, et al. Carbon sequestration in the deep Atlantic enhanced by Saharan dust. Nature Geosci. 2017;10:189.

4. Jiao N, Robinson C, Azam F, Thomas H, Baltar F, Dang H, et al. Mechanisms of microbial carbon sequestration in the ocean-future research directions. Biogeosciences. 2014;11:5285.

5. Rae JWB, Burke A, Robinson LF, Adkins JF, Chen T, Cole C, et al. $\mathrm{CO}_{2}$ storage and release in the deep Southern Ocean on millennial to centennial timescales. Nature. 2018;562:569.

6. Sigman D, Boyle E. Glacial/interglacial variations in atmospheric carbon dioxide. Nature. 2000;407:859.

7. Bauer JE, Cai WJ, Raymond PA, Bianchi TS, Hopkinson S, Regnier PAG. The changing carbon cycle of the coastal ocean. Nature. 2013;504:61. 
8. Gruber N, Clement D, Carter BR, Feely RA, van Heuven S, Hoppema M, et al. The oceanic sink for anthropogenic $\mathrm{CO}_{2}$ from 1994 to 2007. Science. 2019;363(6432):1193.

9. Boyd PW, Claustre H, Levy M, Siegel DA, Weber T. Multi-faceted particle pumps drive carbon sequestration in the ocean. Nature. 2019;568:327-35.

10. Favero A, Daigneault A, Sohngen B. Forests. Carbon sequestration, biomass energy, or both? Sci Adv. 2020;6(13):eaay6792.

11. Joint I, Doney S, Karl D. Will ocean acidification affect marine microbes? ISME J. 2011;5:1-7.

12. Hutchins D, Fu F. Microorganisms and ocean global change. Nat Microbiol. 2017;2:17058.

13. Jiao N, Herndl GJ, Hansell DA, Benner R, Kattner G, Wilhelm SW, et al. Microbial production of recalcitrant dissolved organic matter: long-term carbon storage in the global ocean. Nat Rev Microbiol. 2010;8:593-9.

14. Resplandy L, Keeling RF, Rödenbeck C, Stephens BB, Khatiwala S, Rodgers KB, et al. Revision of global carbon fluxes based on a reassessment of oceanic and riverine carbon transport. Nature Geosci. 2018;11:504-9.

15. Legendre L, Rivkin RB, Weinbauer MG, Guidi L, Uitz J. The microbial carbon pump concept: Potential biogeochemical significance in the globally changing ocean. Prog Oceanogr. 2015;134:432-50.

16. Mentges A, Feenders C, Deutsch C, Blasius B, Dittmar T. Long-term stability of marine dissolved organic carbon emerges from a neutral network of compounds and microbes. Sci Rep. 2019;9:17780.

17. García-Martín E, Aranguren-Gassis E, Hartmann MM, Zubkovc MV, Serreta P. Microbial production of recalcitrant dissolved organic matter: long-term carbon storage in the global ocean. Prog Oceanogr. 2017;158:593-9.

18. Zhou YJ, Kerkhoven EJ, Nielsen J. Barriers and opportunities in bio-based production of hydrocarbons. Nat Energy. 2018;3:925-35.

19. Yu S, Jain PK. Plasmonic photosynthesis of $\mathrm{C}_{1}-\mathrm{C}_{3}$ hydrocarbons from carbon dioxide assisted by an ionic liquid. Nat Commun. 2019;10:2022-9.

20. Zhou Y, Grice K, Stuart-Williams H, Farquhar GD, Hocart CH, Lu H, Liu W. Biosynthetic origin of the saw-toothed profile in $\delta 13 \mathrm{C}$ and $82 \mathrm{H}$ of n-alkanes and systematic isotopic differences between $\mathrm{n}$-, iso- and anteiso-alkanes in leaf waxes of land plants. Phytochemistry. 2010;71:388-403.

21. Schirmer A, Rude MA, Li X, Popova E, Del Cardayre SB. Microbial biosynthesis of alkanes. Science. 2010;329:559-62.

22. Esparza M, Cárdenas JP, Bowien B, Jedlicki E, Holmes DS. Genes and pathways for $\mathrm{CO}_{2}$ fixation in the obligate, chemolithoautotrophic acidophile, Acidithiobacillus ferrooxidans, Carbon fixation in $A$. ferrooxidans. BMC Microbiol. 2010;10:229-43.

23. Jones S. Five ways to cycle carbon. Nat Rev Microbiol. 2008;6:95.

24. Figueroa IA, Barnum TP, Somasekhar PY, Carlström Cl, Engelbrektson AL, Coates JD. Metagenomicsguided analysis of microbial chemolithoautotrophic phosphite oxidation yields evidence of a seventh 
natural $\mathrm{CO}_{2}$ fixation pathway. Proc. Natl. Acad. Sci. U. S. A. 2018;115: E92-E101.

25. Rubin-Blum M, Dubilier N, Kleiner M. Genetic Evidence for Two Carbon Fixation Pathways (the CalvinBenson-Bassham Cycle and the Reverse Tricarboxylic Acid Cycle) in Symbiotic and free-living bacteria. mSphere. 2019;4:e00394-18.

26. Hiras J, Wu YW, Eichorst SA, Simmons BA, Singer SW. Refining the phylum Chlorobi by resolving the phylogeny and metabolic potential of the representative of a deeply branching, uncultivated lineage. ISME J. 2016;10:833-45.

27. Ni J, Liu HY, Tao F, Wu YT, Xu P. Remodeling of the photosynthetic chain promotes direct $\mathrm{CO}_{2}$ conversion to valuable aromatics. Angew. Chemie - Int Ed. 2018;57:15990-4.

28. Liu X, Miao R, Lindberg P, Lindblad P. Modular engineering for efficient photosynthetic biosynthesis of 1-butanol from $\mathrm{CO}_{2}$ in cyanobacteria. Energy Environ Sci. 2019;12:2765-77.

29. Scrutton NS. Enzymes make light work of hydrocarbon production. Science. 2017;357:872-3.

30. Doukov TI, Iverson TM, Seravalli J, Ragsdale SW, Drennan CL. A Ni-Fe-Cu Center in a bifunctional carbon monoxide dehydrogenase/Acetyl-CoA synthase. Science. 2002;298:567-72.

31. Verschueren KHG, Blanchet C, Felix J, Dansercoer A, De Vos D, Bloch Y, et al. Structure of ATP citrate lyase and the origin of citrate synthase in the Krebs cycle. Nature. 2019;568:571-5.

32. Takai K, Campbell BJ, Craig Cary S, Suzuki M, Oida H, Nunoura T, et al. Enzymatic and genetic characterization of carbon and energy metabolisms by deep-sea hydrothermal chemolithoautotrophic isolates of Epsilonproteobacteria. Appl Environ Microbiol. 2005;71:7310-20.

33. Pérez-Etayo L, de Miguel MJ, Conde-Álvarez R, Muñoz PM, Khames M, Iriarte M, Moriyón I, ZúñigaRipa A. The $\mathrm{CO}_{2}$-dependence of Brucella ovis and Brucella abortus biovars is caused by defective carbonic anhydrases. Vet Res. 2018;49:85.

34. Shimamura T, Watanabe S, Sasaki S. Enhancement of enterotoxin production by carbon dioxide in Vibrio cholerae. Infect Immun. 1985;49:455-6.

35. Rasigraf O, Kool DM, Jetten MSM, Sinninghe Damsté JS, Ettwig KF. Autotrophic carbon dioxide fixation via the Calvin-Benson-Bassham cycle by the denitrifying methanotroph "Candidatus Methylomirabilis oxyfera. Appl Environ Microbiol. 2014;80:2451-60.

36. Kumar M, Gazara RK, Verma S, Kumar K, Verma PK, Thakur IS. Genome sequence of carbon dioxidesequestering Serratia sp. strain ISTD04 isolated from marble mining rocks. Genome Announc. 2016;4:e01141-16.

37. Javor BJ. $\mathrm{CO}_{2}$ fixation in Halobacteria. Arch Microbiol. 1988;149:433-40.

38. Adam PS, Borrel G, Gribaldo S. An archaeal origin of the Wood-Ljungdahl H4MPT branch and the emergence of bacterial methylotrophy. Nat Microbiol. 2019;4:2155-63.

39. Berg IA, Daniel Kockelkorn D, Hugo Ramos-Vera W, Say RF, Zarzycki J, Hügler M, Alber BE, Fuchs G. Autotrophic carbon fixation in Archaea. Nat Rev Microbiol. 2010;8:447-60.

40. Muchowska KB, Varma SJ, Moran J. Synthesis and breakdown of universal metabolic precursors promoted by iron. Nature. 2019;569:104-7. 
41. Igarashi Y, Kodama T. Genes related to carbon dioxide fixation in Hydrogenovibrio marinus and Pseudomonas hydrogenothermophila. In: Lidstrom ME, Tabita FR, editors. Microbial Growth on C1 Compounds. Dordrecht: Springer; 1996. pp. 88-93.

42. Diender M, Stams AJM, Sousa DZ. Pathways and bioenergetics of anaerobic carbon monoxide fermentation. Front Microbiol. 2015;6:1275-93.

43. Sickerman NS, Lee CC, Ohki Y, Tatsumi K, Ribbe MW, Hu Y. Reduction of C1 substrates to hydrocarbons by the homometallic precursor and synthetic mimic of the nitrogenase Cofactor. J Am Chem Soc. 2017;139:603-6.

44. Fixen KR, Zheng Y, Harris DF, Shaw S, Yang ZY, Dean DR, et al. Light-driven carbon dioxide reduction to methane by nitrogenase in a photosynthetic bacterium. Proc. Natl. Acad. Sci. U. S. A. 2016;113: 10163-10167.

45. Lee CC, Hu Y, Ribbe MW. Reduction and condensation of aldehydes by the isolated cofactor of nitrogenase. ACS Cent Sci. 2018;4:1430-5.

46. Khara B, Menon N, Levy C, Mansell D, Das D, Marsh ENG, et al. Production of propane and other short-chain alkanes by structure-based engineering of ligand specificity in aldehyde deformylating oxygenase. Chembiochem. 2013;14:1204-8.

47. Park MO. New pathway for Long-chain $\mathrm{n}$-alkane synthesis via 1-alcohol in Vibrio furnissii M1. J Bacteriol. 2005;187:1426-9.

48. Yakunin AF, Hallenbeck PC. Short-Term Regulation of Nitrogenase activity by $\mathrm{NH} 4+$ in Rhodobacter capsulatus. Multiple in vivo Nitrogenase responses to $\mathrm{NH} 4+$ addition. J Bacteriol. 1998;180(23):6392-5.

49. Sheppard MJ, Kunjapur AM, Prather KLJ. Modular and selective biosynthesis of gasoline-range alkanes. Metab Eng. 2016;33:28-40.

50. Zhang WY, Ma M, Huijbers MME, Filonenko GA, Pidko EA, van Schie M. Hydrocarbon synthesis via photoenzymatic decarboxylation of carboxylic acids. J Am Chem Soc. 2019;141(7):3116-20.

51. Moulin S, et al. Continuous photoproduction of hydrocarbon drop-in fuel by microbial cell factories. Sci Rep. 2019;9:13713.

52. Aukema KG, et al. Cyanobacterial aldehyde deformylase oxygenation of aldehydes yields n-1 aldehydes and alcohols in addition to alkanes. ACS Catal. 2013;3:2228-38.

53. Caporaso JG, Lauber CL, Walters WA, Berg-Lyons D, Lozupone CA, Turnbaugh PJ, et al. Global patterns of $16 \mathrm{~S}$ rRNA diversity at a depth of millions of sequences per sample. Proc. Natl. Acad. Sci. U. S. A. 2011;108:4516-4522.

54. Takahashi S, Tomita J, Nishioka K, Hisada T, Nishijima M. Development of a prokaryotic universal primer for simultaneous analysis of bacteria and archaea using next-generation sequencing. PLoS One. 2014;9:e105592.

55. Jiang N, Zheng C, Chen L, Wei K, Feng J, Tian J. Characteristic microbial communities in the continuous permafrost beside the bitumen in Qinghai-Tibetan Plateau. Environ Earth Sci. 2015;74:1343-52. 
56. Caporaso JG, Kuczynski J, Stombaugh J, Bittinger K, Bushman FD, Costello EK, Fierer N, et al. QIIME allows analysis of high-throughput community sequencing data. Nat Methods. 2010;7:335-6.

57. DeSantis TZ. Greengenes, a chimera-checked 16S rRNA gene database and workbench compatible with ARB. Appl Environ Microbiol. 2006;72:5069-72.

58. Bolger AM, Lohse M, Usadel B. Trimmomatic: a flexible trimmer for Illumina sequence data. Bioinformatics. 2014;30:2114-20.

59. Li D, Liu CM, Luo R, Sadakane K, Lam TW. MEGAHIT: an ultra-fast single-node solution for large and complex metagenomics assembly via succinct de Bruijn graph. Bioinformatics. 2015;31:1674-6.

60. Seemann T. Prokka: rapid prokaryotic genome annotation. Bioinformatics. 2014;30:2068-9.

61. Patro R, Duggal G, Love MI, Irizarry RA, Kingsford C. Salmon provides fast and bias-aware quantification of transcript expression. Nat Methods. 2017;14:417-9.

62. Wu YW, Tang YH, Tringe SG, Simmons BA, Singer SW. MaxBin: an automated binning method to recover individual genomes from metagenomes using an expectation-maximization algorithm. Microbiome. 2014;2:26.

\section{Abbreviations}

MCP: Microbial Carbon Pump

BCP: Biological carbon pump

DOC: Dissolved organic carbon

GC-MS: Gas chromatography-mass spectrometry

OTUs: Operational taxonomic units

CBB: Calvin-Benson-Bassham

WL: Wood-Ljungdahl

rTCA: Reductive tricarboxylic acid

AD: Aldehyde decarbonylase

CODH: Carbon monoxide dehydrogenase

CARs: Carboxylic acid reductase

\section{Declarations}

\section{Ethics approval and consent to participate}


Not applicable

\section{Consent for publication}

Not applicable

\section{Availability of data and materials}

All raw reads of $16 \mathrm{~S}$ rRNA and metagenomic sequencing had been deposited at Sequence Read Archive under accession number PRJNA577349 and PRJNA512068. 16S rRNA sequencing data of several facultatively and obligately anaerobic strains have been deposited as GeneBank access No. MN538968 to MN538983.

\section{Competing interests}

The authors declare no competing interests.

\section{Funding}

This study was supported by the China National Key Research and Development Project (2018YFA0902101) and National Natural Science Foundation of China (41773080).

\section{Authors' contributions}

WX, YT and TM initiated the project. WX developed the photo-driven bioprocess, performed the characterizations (GC, GC-MS, 16S rRNA and metagenomic sequencing) the $\mathrm{CO}_{2}$ bioconversion studies, stain isolation, and analysis of the data. RC and YL carried out data analysis of 16S rRNA and metagenomic sequencing. WX carried out pathway analysis. WX and YT supervised the research. WX, RC, $\mathrm{YL}, \mathrm{YT}$, and TM contributed to the interpretation of the data and preparation of the manuscript.

\section{Acknowledgments}

We thank Prof. William A. Goddard (at California Institute of Technology) for assistance with nitrogenase analysis, and Dr. Shaojin Wang (at Department of microbiology, Nankai University) for assistance with metagenomic analysis; Dr. Jing Zhao for the assistance of reaction energy analysis and setup of photoreactor.

\section{Figures}


A

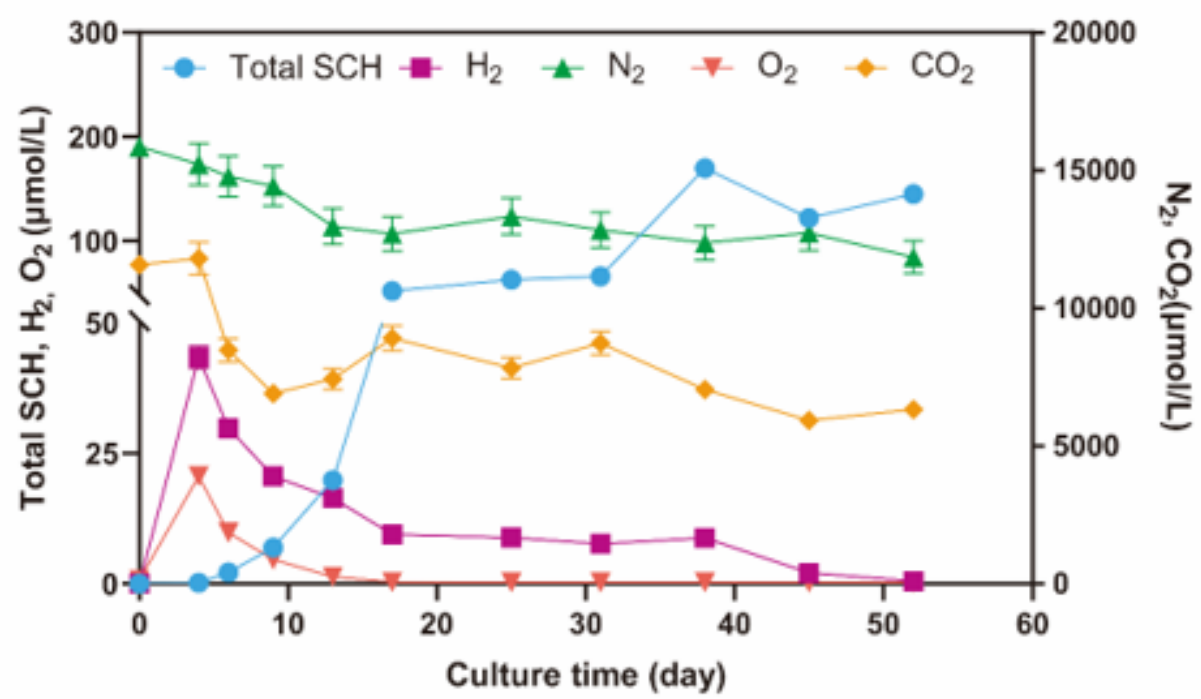

B

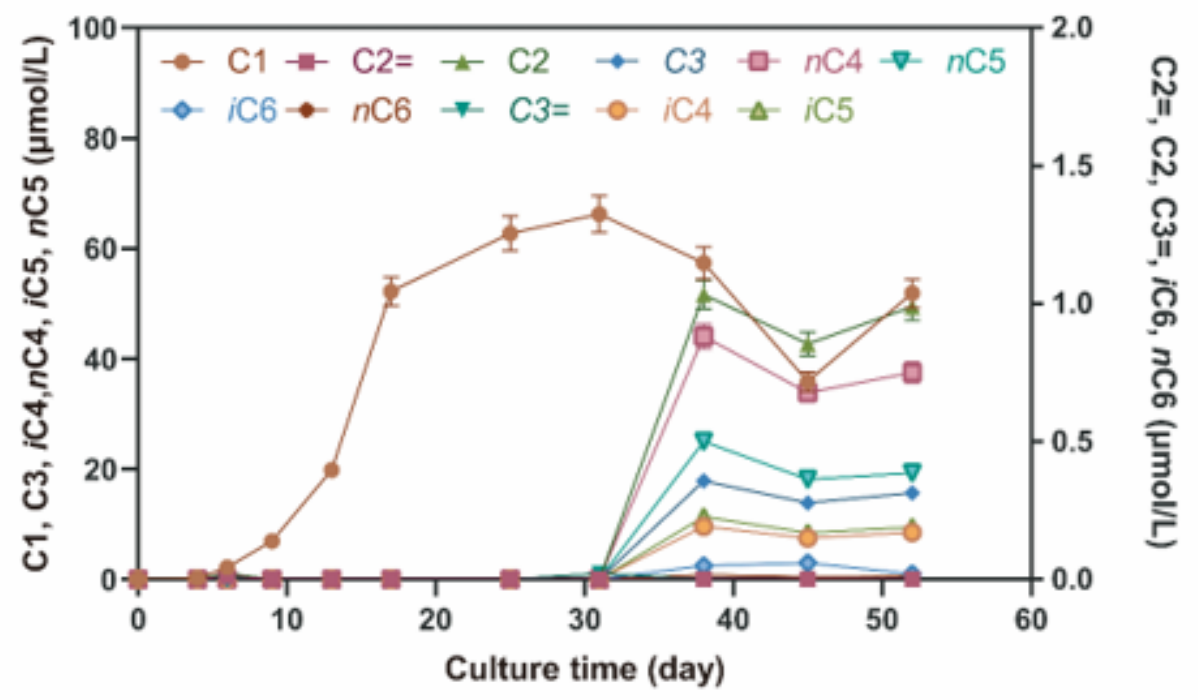

Figure 1

Conversion of carbon dioxide to short-chain hydrocarbons by long-term cultivation of the enriched microbial community. A) Detection of total synthesized hydrocarbons, oxygen, dinitrogen, carbon dioxide, and hydrogen; B) C1-C6 alkanes or alkenes were detected through the culturing, when carbon dioxide as solo carbon source with exposed to LED light. 


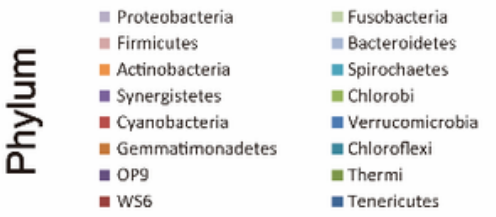
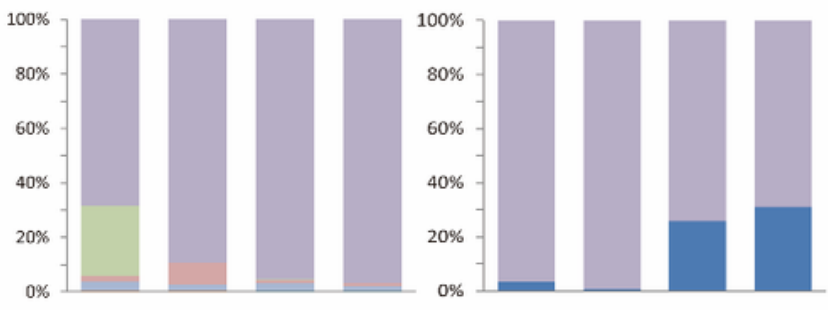

= Euryarchaeota

- Crenarchaeota

Gammaproteobacteria = Fusobacteriia

= Alphaproteobacteria = Clostridia

- Deltaproteobacteria = Epsilonproteobacteria

Sphingot

Sphingobacterii

- Actinobacteria

- Ignavibacteria

- Cytophagia

= Epsilonproteobacteria

E Betaproteobact
a Flavobacteriia

Bacilli

= Synergistia

- Erysipelotrichi

- Verrucomicrobiae

= Chloroplast

mother

- Enterobacteriales

= Alteromonadales

- Rhodobacterales

= Oceanospirillales

- Burkholderiales

- Sphingobacteriales

- Rhizobiales

- Actinomycetales

= Pseudomonadales

= Fusobacteriales

$=$ Clostridiales

= Campylobacterales

= Bacteroidales

= Xanthomonadales

- Vibrionales

- Flavobacteriales

- Lactobacillales

mother
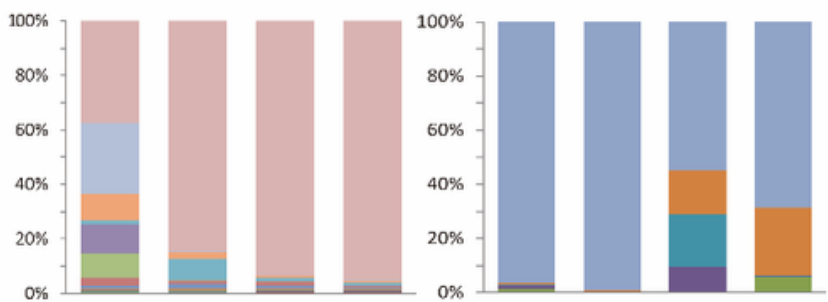

Methanomicrobis

MCG

- Methanobacteria

- Thaumarchaeota

- MBGB

- MBGA

- Thermoplasmata
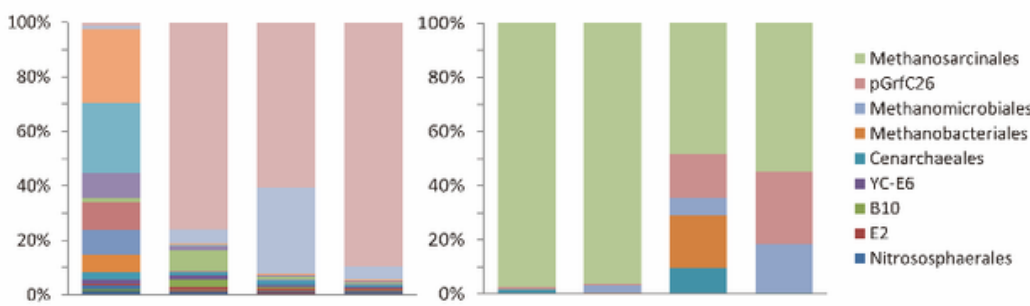

Enterobacteriaceae

- Alteromonadacese

= Pseudomonadaceae

= Fusobacteriaceae

= Rhodobacteraceae = Desulfovibrionaceae

- Campylobacteraceae $=$ Oceanospirillaceae

- $\$ 24.7$

- Sphingobacteriaceae

= Clostridiaceae

- Flavobacteriaceae

- Comamonadaceac

- Alcaligenaceae

- Bacteroidaceae

- Moraxellaceae

- Lachnospiraceae

w other
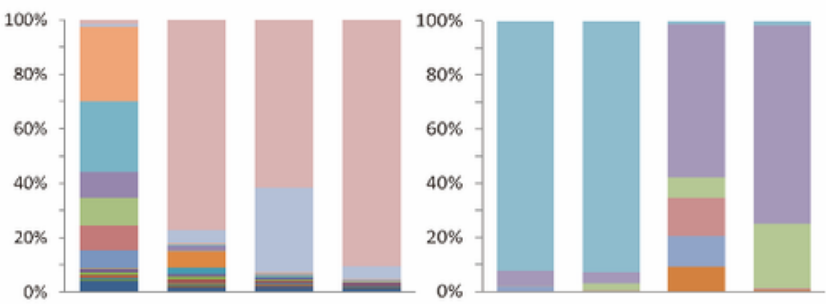

Methanosarcinaceac

- Methanosaetaceae

WSA2

- Cenarchaeaceae

Mcthanobactcriaceac

- Methanoregulaceae

Methanomicrobiacea

= Marine group II

= Methanomassiliicoccaceae

Nitrososphacraccac

Pseudomonas $=$ Serratia

= Marinobacter $\quad$ = Propionigenium

Marinobacter

m Arcobacter

- Marinobacterivm

Bacteroides

$\begin{array}{ll}\text { - Clostridium } & \text { Lactobacillus } \\ \text { Vibrio } & \text { Treponema }\end{array}$

- Marinomonas a Thalassospira

- Marinomonas

Psychrobacter

= Serratio marcesecens

mother
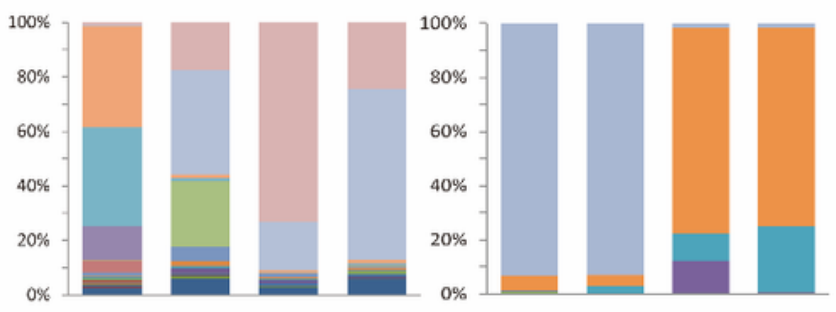

Methanosarcina

= Methanosaeta

methanospirillum

- Methanobacterium

- Nitrosopumilus

- Methanolinea

- Methanoculleus

- Methanomassiliicoccus

- Methanobrevibacter

- Candidatus Nitrososphaera

- Methanosphacra

- Candidatus Methanoregula

= Vibrio shilonii

$=$ Bacteroides acidifaciens

$=$ Marinobacter hydrocarbonoclasticus

= Actinomadura vinacea

Lactobacillus reuteri

= Akkermansia muciniphil

Ruminococcus gnavus

- Bacillus humi

Desulfovibrio aminophilus

- Alcanivorax dieselolel

Brachybacterium conglomeratum

- Shewanella algae

- Luteibacter rhizovicinus

- Blautia producta
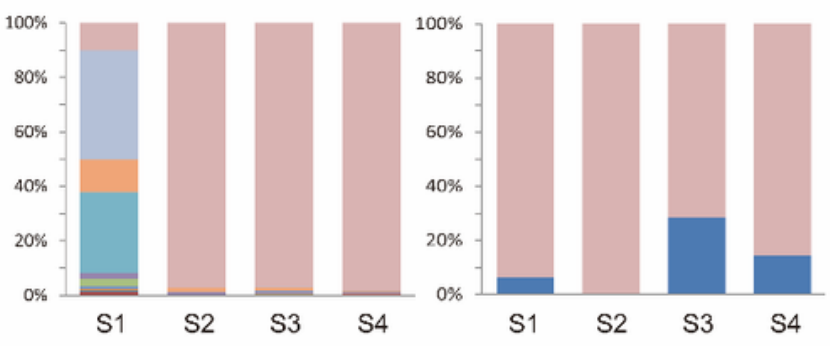

Methanosarcina maze

- Methanobacterium bryantil

Figure 2

DNA samples for community analysis were obtained for all data points. Taxonomic composition of the enriching microbial communities in cultures. Each OTU with an average normalized abundance of $\geq 1 \%$ of the community under any treatment is labeled according to the lowest taxonomic rank assigned to them. Based on 16S rRNA, bacterial and archaea OUTs in various levels. Each dataset represents the average of independently sequenced triplicate cultures. 


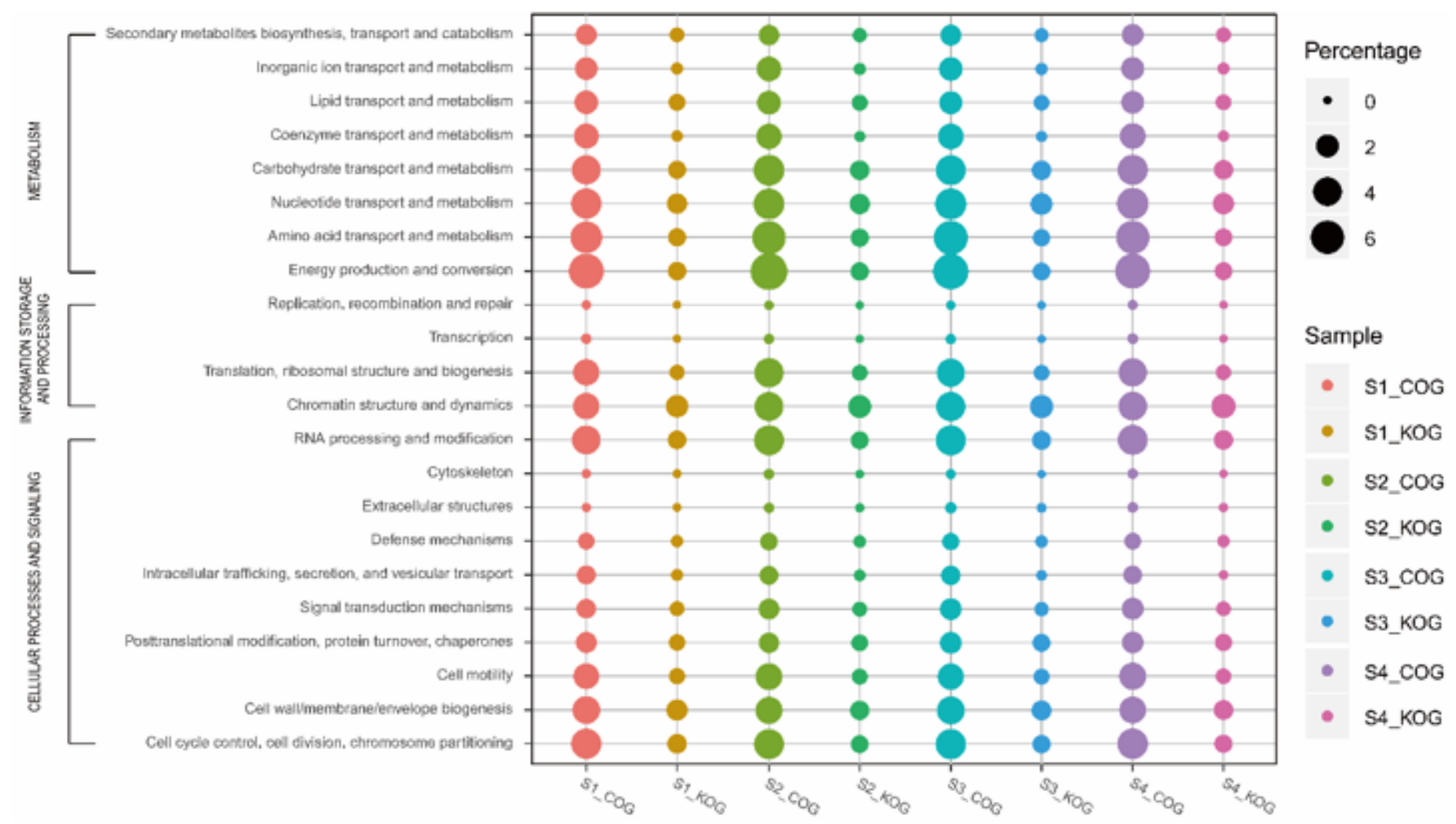

\section{Figure 3}

Functional overview of high-quality binned genomes. The size of the filled circle indicates the presence of the metabolic activities in the corresponding genome from each sample, according to COG (Unicellular orthologs) and KOG (Eukaryote orthologs). A metabolism was considered present only if all genes encoding at least one full enzymatic pathway capable of carrying out that metabolic process were found in the genome. A bioenergetic complex was considered present only if all genes encoding the necessary subunits for a functional protein complex were found in the genome. 

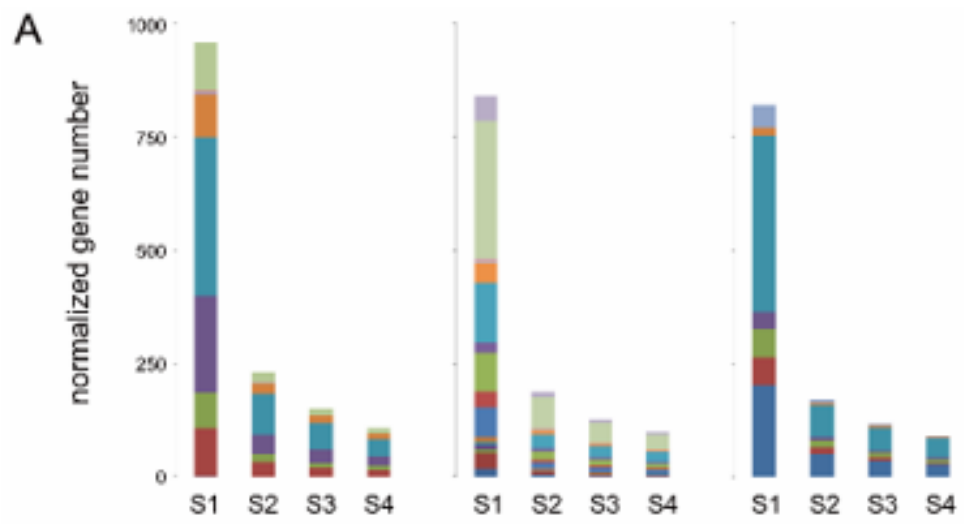

CBB cycle (M00165)

In tassketolase

Intesoieptiose

aroulose

- rtanos

Ehoshoribuiokinase

Ehoshogycerate

Elyceraidetyde

- tuctose

rTCA cycle (M00173)

= succiny-COA_synthetase

III wusenale_clatydrogenase

II pyovate_water_dikinate

III Dyruate_ontrophosphete_exinase

II Pyvvate_foredecin_axdereductase

E pyuvate_cabaxylave

E phosshoenolpynivate_carboxyluse

II melase_dehydrogesese

E isoctran_dehydropenese

E Emarale_mocuciase

E tumarale Higdatase

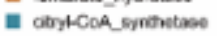

- atri-CoA lyase

in ATP-itratn lyemo

- acchtole hydrases

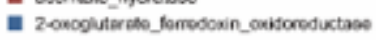

WL pathway (M00377)

E

in smetryt:torchyorotoile_cortinokd

in actey-Cox_syntase

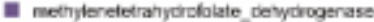

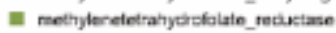

E anaprotic_cartion-monowde_dehydroginase

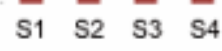

CBB cycle

(M00165)

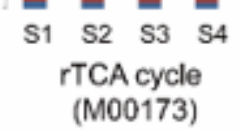

$\begin{array}{llll}\mathrm{S1} & \mathrm{S} 2 & \mathrm{S3} & \mathrm{S4}\end{array}$

- tormato_schyerogonateso

WL pathway

(M00377)

\section{Figure 4}

Accumulated gene abundance for the completed pathways of carbon dioxide fixation. Calvin-Benson cycle (M00165), Reductive citrate cycle (M00173), and WL pathway (M00377) from all samples. 

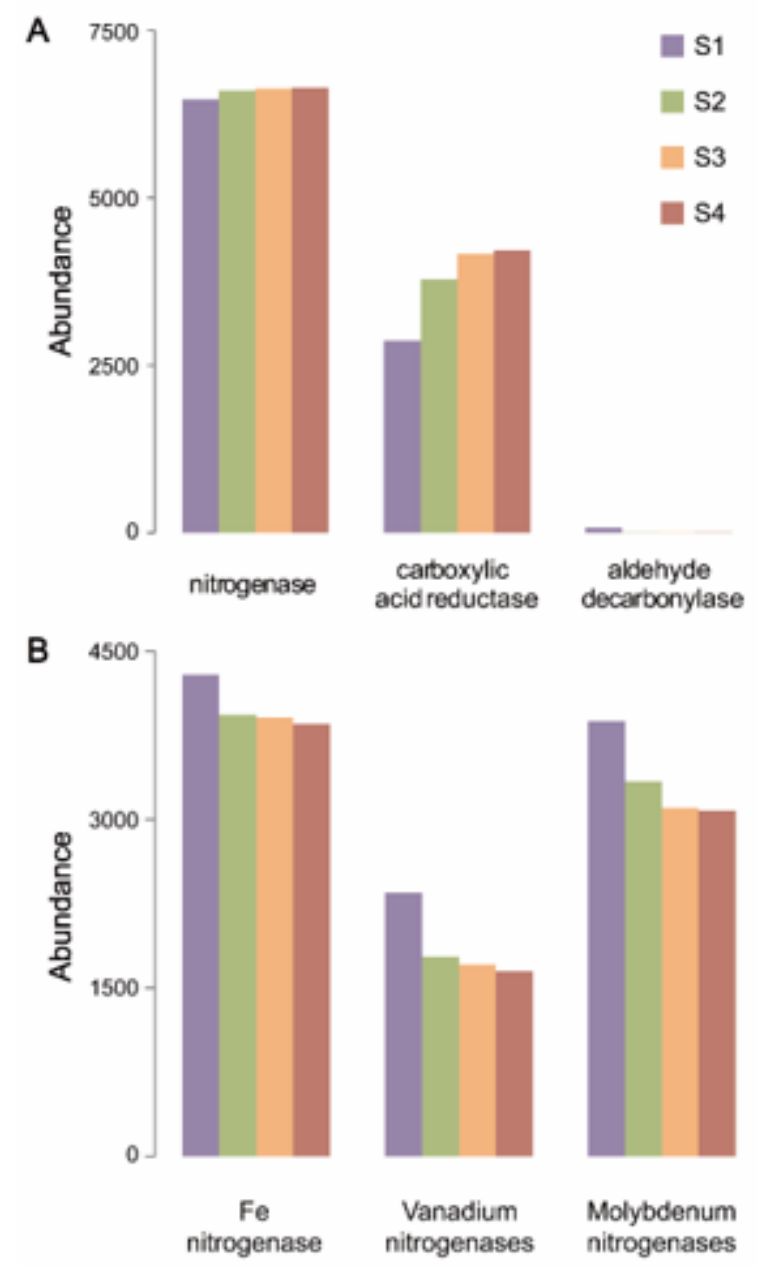

Figure 5

Comparison of accumulated gene abundance of hydrocarbon synthesis. a) among the nitrogenase, and carboxylic acid reductase, aldehyde decarbonylase, and $b$ ) within three types of nitrogenases. 


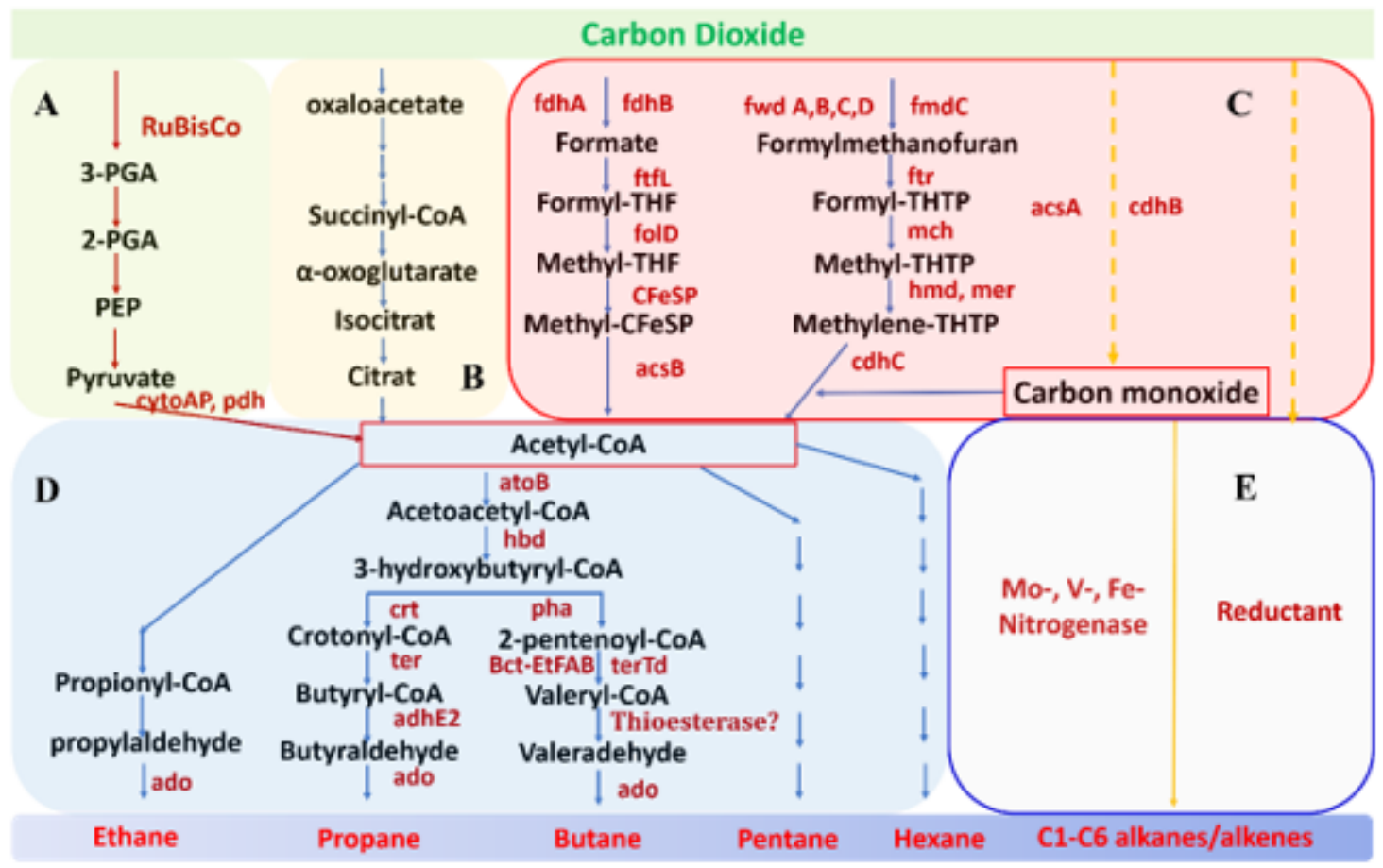

\section{Figure 6}

Schematic pathway for our bioconversion process from carbon dioxide to short chain hydrocarbons. Based on the analysis of metabolites, 16S rRNA sequencing, and metagenomic sequencing. (A) represents Calvin-Benson cycle. (B) represents reductive citrate cycle. (C) represents WL pathway. (D) represents the pathway of hydrocarbon synthesis with $A D O$ and $C A R$, and $(E)$ represents the pathway of hydrocarbon synthesis with nitrogenase. 

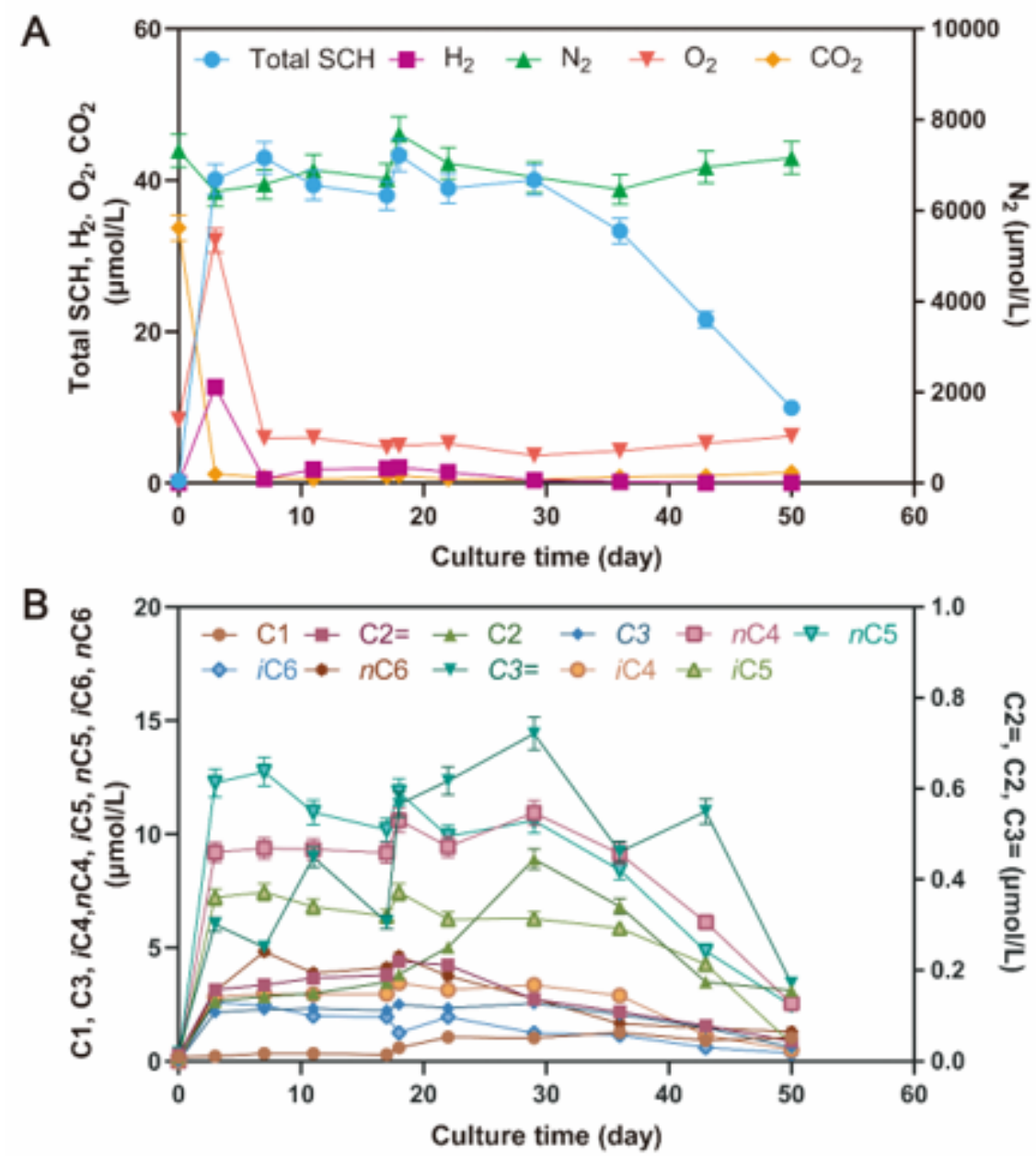

Figure 7

Conversion of carbon dioxide to short chain hydrocarbons by a long-term cultivation of the developed biogroup with the purposeful combination of the isolated microbes. A) Detection of oxygen, dinitrogen, carbon dioxide, and hydrogen; B) C1-C6 alkanes or alkenes were detected through the culturing, when when carbon dioxide as solo carbon source with exposed to LED light.

\section{Supplementary Files}

This is a list of supplementary files associated with this preprint. Click to download.

- Supplementary202007.docx 